\title{
Editorial \\ Theorising health inequalities: Introduction to a double special issue
}

Social Theory \& Health (2015) 13, 219-226. doi:10.1057/sth.2015.25

In December, 2012, a symposium to explore and debate future directions for health inequalities research, Where Next for Health Inequalities? (www.health inequalities.net/) was co-organised by one of us (KS) at the University of Edinburgh. One of the themes that emerged from discussions at this symposium, as well as in a series of interviews with researchers and policy actors undertaken in advance of this event (Smith, 2013), was an evident concern, among both researchers and policymakers, about the limited range of theories that contribute to explaining the origins and implications of health inequalities. This was the start of the long and winding road that has led to the production of this special issue. We have divided the issue into two parts: the articles in Part 1 focus on outlining, employing or refining theories that are intended to help us better understand the production of health inequalities; whereas the articles in Part 2 are more concerned with how various theories can help us think about (actual and potential) responses to these inequalities.

Lewin (1951, p. 169) famously reflected that there is 'nothing more practical than a good theory'. Yet in health inequalities research, and public health more broadly, the number of theoretical contributions pales in comparison to the evergrowing number of empirical studies. It is certainly true that most of these empirical studies are informed by social theory in that many employ indicators of social categories that reflect theoretical ideas sketched out by Marx, Engels and Weber (see Kapilashrami et al and Scambler and Scambler, this issue) but these theoretical underpinnings are rarely acknowledged, interrogated or considered in any detail. Where theoretical frameworks have been applied to the study of health inequalities, this has often been with the purpose of trying to understand, or help analyse, pre-existing data sets or findings, rather than to inform decisions about how we study, and try to tackle, such inequalities or to develop theoretical approaches that are specifically intended to help us better understand health inequalities as a phenomenon. The collection of articles in this special issue is an attempt to begin redressing the empirical bias described here; to demonstrate some of the practical implications that social theories have to offer those seeking to better understand, and tackle, a social problem as complex and persistent as

(C) 2015 Macmillan Publishers Ltd. 1477-8211 Social Theory \& Health Vol. 13, 3/4, 219-226 www.palgrave-journals.com/sth/ 
health inequalities; and to illustrate the indispensability of theory in generating new hypotheses for empirical research, both qualitative and quantitative.

In this short introduction, rather than try to summarise each article in turn (work that is already available via the article abstracts), we draw out six key themes that seem to cut across the eleven contributions making up this special issue and consider the implications arising from each for future health inequalities research.

The first and perhaps most obvious theme, and the one to which we devote the most space in this introduction, is 'critical thinking', with each of the 11 contributions providing critical perspectives on familiar ways of thinking about health inequalities. The focus of these criticisms includes a tendency within health inequalities research to employ restricted, individualistic categories to study social phenomena (Kapilashrami et al; Muntaner et al; Scambler and Scambler) and a preoccupation with empirical data which, in turn, has led to a focus on crosssectional (rather than longitudinal and time-sensitive) data (Muntaner et al). In part, this reflects the substantial body of research on health inequalities that has relied on categories and indicators that were available in existing large data sets (Kapilashrami et al; Muntaner et al). This brings to mind the old story about the drunk looking for his keys under a lamp-post, even though he dropped them in the dark. While it is difficult to criticise research for limitations that were often beyond the control of the researchers, the contributions to this special issue make clear the urgent need for more theoretically informed research designs.

Moving from the design of research to its write-up and articulation (both to other researchers and to wider, policy and public audiences), two of the articles (Scambler and Scambler; Scott-Samuel and Smith) argue that contributors to health inequalities debates have not been sufficiently clear about the inherent contradictions within capitalism and between economic policy goals and policy commitments to reducing health inequalities. Weinstock's contribution goes beyond this to argue that, in not adequately considering the multiple policy goals with which governments and societies are faced and the potential trade-offs between these (for example, between economic and health goals), health inequalities researchers have failed to articulate a theory of justice that supports their calls for greater policy attention to be paid to addressing the social determinants of health (and their equitable distribution).

In taking stock of the kinds of theories that have been employed by health inequalities researchers, three of the articles in this special issue (Beckfield et al, Raphael and Bryant and Garnham) recognise the contribution made by researchers who have applied Esping-Andersen's 'worlds of welfare' framework to try to understand the impacts of different policy packages on health inequalities but all three articles also highlight weaknesses in this body of work. They note, for example, that placing countries into broad and fixed welfare state categories implies a consistency across countries and policies and over time that is 
misleading. Each paper then provides an alternative view as to how future research might best avoid the potentially obfuscating nature of such analysis. Raphael and Bryant suggest supplementing a 'worlds of welfare' framework with theories concerning the importance of the lifecourse; theories about the historical and cultural contexts in which public and policy debates take place; and theories concerning power and the influence of profit-seeking entities (particularly large corporations) on policies affecting social determinants of health and their distribution. Beckfield and colleagues' contribution is more ambitious and involves drawing on the rich history of institutional theories to set out a new, institutional theoretical framework for thinking about how different welfare states affect health inequalities via a range of policies that go beyond straightforward redistribution of income. Both contributions, and indeed others in the issue, move beyond the familiar trinity of material, cultural-behavioural and psychosocial explanations of health inequalities and aim to enhance our understanding of the vexed question of how we should understand the relation between welfare state characteristics and the distribution (rather than the average level) of health over the life course.

Taking a rather different theoretical focus, the contributions from Collins and colleagues, Muntaner and colleagues, Scambler and Scambler and Smith all build on, while critiquing, particular threads of Marxist or Neo-Marxist analysis within health inequalities research. For Muntaner and colleagues, prevailing understandings of class in terms of individual attributes are less informative than an approach rooted in analytical Marxism (especially the work of Erik Olin Wright), which emphasises social class in terms of class relations that give persons control over productive assets and the labour power of others. Like the Lancet-University of Oslo Commission on Global Governance for Health (Ottersen et al, 2014), Scambler and Scambler emphasise the roots of health inequalities in unequal distributions of power, which in their view are largely neglected in social epidemiology and population health research. Smith on the other hand asks whether post-structural theories, which emphasise the fluid and ephemeral nature of power, have anything to offer structural/Marxist accounts of the links between political context and health inequalities.

Moving beyond the weaknesses of existing ways of thinking about health inequalities, several of the papers take explicit and direct aim at the beneficiaries of growing inequalities in wealth and power, with Raphael and Bryant, Scambler and Scambler and Scott-Samuel and Smith all calling for health inequalities researchers to do more to analyse the hyper-concentration of wealth. Scambler and Scambler directly connect the rise of economic inequality under a new form of financial capitalism with health inequalities, stating starkly that: 'The lining of the pockets of the less-than 1 per cent kills people'. The policy relevance of this call in (for example) the UK context, where working people are still recovering 
from the effects of the 2008 financial crisis while the wealth of Britain's richest thousand families has doubled, cannot be over-emphasised.

The second theme is dynamism and 'time', with almost all of the contributions challenging health inequalities researchers to do more to better capture the various ways in which the processes and mechanisms shaping health inequalities are in constant flux, evolving over time. Beckfield and colleagues, Collins and colleagues, Muntaner and colleagues, Raphael and Bryant, Scambler and Scambler and Smith all highlight the need for theoretical frameworks that draw attention to historical processes so that we better understand not just how particular policies impact on health inequalities, but how and why those policies arise. Several of these contributions also draw attention to the need for research that allows for the ongoing evolution of the social categories we employ, with Kapilashrami and colleagues explicitly calling for fresh approaches to studying health inequalities that emphasise 'social dynamics rather than social categories'. Garnham's more empirical contribution provides a magnificently nuanced account of how the relations between place and health can change over time. Like several other articles, Garnham's contribution identifies the micro-scale mechanisms that are functioning to shape people's varied experiences of health and well-being but she is (in our view) especially effective in using theoretical concepts (from Swidler) to connect individuals, local places and the deepening of spatial inequalities with macro-scale processes like deindustrialisation and policy choices such as privatisation and social policy retrenchment. Such micro-macro linkages constitute, in our view, an important area for future research (for an early contribution that did not specifically address health but in retrospect looks remarkably prescient, see Beynon et al, 1994).

In a similar vein, the third theme connecting many of the articles in this special issue relates to the complexity of the influences on health inequalities; this is the importance of multiplicity and intersectionality. Kapilashrami and colleagues, Muntaner and colleagues and Scambler and Scambler all reflect on the limitations inherent in popular ways of conceptualising the relationships between social class and health, calling on researchers to develop empirical research programmes that are better informed by rich theoretical accounts of social class and which recognise the multiple and intersecting factors that shape people's social location and, in turn, their health experiences. Kapilashrami and colleagues' paper is, however, the only one to move substantially beyond class to provide a detailed consideration of other axes of social position. Drawing on feminist work on intersectionality, they argue the need for explanations of health inequalities that incorporate 'multiple axes of social position' such as ethnicity, gender and caste as 'multiple layers of advantage and disadvantage [that are] relevant for health inequalities'. Focusing more on the ways in which multiple policies intersect to shape people's lived experiences, Beckfield and colleagues, and Raphael and Bryant also draw attention to 
the multi-dimensional and intersecting nature of the social determinants underlying health inequalities.

The fourth theme is 'imagination', which is a focus for Collins and colleagues, Scambler and Scambler and Scott-Samuel and Smith. While Collins and colleagues' contribution helps us better understand why health inequalities researchers have failed 'to project evidence on health inequalities into the policy imagination', Scambler and Scambler and Scott-Samuel and Smith both highlight the necessity of making space for 'visionaries' within health inequalities who can help us 'speculate' about possible future alternatives to current social, political and economic arrangements. Indeed, Scott-Samuel and Smith argue that the lack of any clear visions of the kind of large-scale social change needed to address the structural origins of health inequality has left health inequalities research open to charges of 'impossibilism' and 'utopianism'. Yet, as they go on to argue, we need 'utopian' thinking - or, in Donna Haraway's words, 'effective social imaginaries' - to enable us to move beyond an analysis of how society is, to consider how it might be. Both the political disenchantment evident in the powerful narratives provided by Garnham's case study of Clydebank and the UK election result of 2015, with its probable consequences for health inequalities, demonstrate what happens when clear and credible pictures of a progressive future are lacking. Hence, the health inequalities field now needs to move beyond an analysis of patterns and causes of health inequalities to start to articulate explicit alternative future scenarios in which greater health equality could be achieved. The alternative is a health inequalities research and policy 'industry' in which the same ideas are endlessly recycled and refined.

A fifth theme is a concern to draw attention to the normative and democratic dimensions of efforts to achieve reductions in health inequalities. This is most clearly foregrounded in Weinstock's article, which sensitises us to the limitations of an approach to health inequity that, whether implicitly or explicitly, holds that health should rank ahead of all other desiderata. 'Health in all policies' may be an increasingly familiar rubric but, Weinstock warns, it must not be read or implemented as 'health above all else in all policies'. Weinstock argues that thinking carefully about the basis on which we are calling for policy action to reduce health inequalities demands some kind of theory of justice, and for Weinstock the preferred approach is a 'political' conception of justice that provides concrete guidance about the kinds of institutions through which this priority-setting should take place. Such an approach suggests the need for health inequalities researchers to focus on power and the ways in which institutions (mal)distribute social goods; an idea that is complementary to, and in some respects provides philosophical foundations for the projects described by Beckwith and colleagues, Raphael and Bryant and Scambler and Scambler.

Moving beyond the need to reflect on the values and assumptions underlying calls to reduce health inequalities, several of the contributions also warn against 
top-down approaches and critically reflect on the tendency of health inequalities researchers to assume that evidence-informed change can be achieved by working directly (and often exclusively) with policy elites rather than taking a more community, grassroots approach to achieving change. Both Collins and colleagues and Scott-Samuel and Smith explicitly call for a democratic and community-based turn to health inequalities research. Muntaner et al point out that a Marxist approach requires recognition that 'the vast majority of the population is on the opposite side of the class struggle than "policymakers" . This observation suggest a further potential dimension for future studies like Smith's, in which the class position of protagonists was not explicitly considered, and points to the need for a critical perspective not only on the call for policyrelevance in population health research (cf. Harper and Strumpf, 2012) but also on the mechanisms by which policy changes that reduce health inequities are achieved. Blencowe and colleagues provide a detailed reflection on the theoretical underpinnings of participatory ways of working. Inspired, in particular, by practices and theories developed in Latin America, they argue that the ambitions of participatory practice among those committed to leftist, egalitarian politics ought to be concentrated on 'overcoming alienation'.

The sixth and final theme is 'action', with many of the articles making space to consider how we might move from an analysis of health inequalities to means of reducing these inequalities. Scambler and Scambler's, Collins and colleagues', and Blencowe and colleagues' contributions are most explicit here. Scambler and Scambler make the case for a further two 'categories' of sociology (and sociologists) to be added to Michael Burawoy's widely cited distinction between professional, policy, critical and public sociologies - these are 'foresight' sociologies (involving the 'visionaries' described above) and 'action' sociologies focusing on 'activists'. Such contributions are necessary, Scambler and Scambler argue, if we are to produce the kind of academic work that moves beyond an analysis of 'what is' to open up alternate, possible worlds. It is this idea that Scott-Samuel and Smith focus on in making the case for utopia as a method in health inequalities. Scambler and Scambler argue instead that Roy Bhaskar's dialectical critical realism provides an appropriate frame for the kind of 'credible, vibrant and engaged' sociology of health inequalities that they are calling for. Collins and colleagues take yet a different approach in their call for a theoretical framework to support action to tackle health inequalities, calling attention to the theoretical contributions of Lev Vygotsky and colleagues, who position human development 'as emerging through people's active transformation of existing environments'. In so doing, this article underscores the potential value of revisiting older bodies of theoretical work that may have been neglected in the social sciences' contemporary dedication to following the latest fashion. Finally, Blencowe and colleagues argue that the kind of participatory research practices 
they outline (drawing on theories of participatory democracy developed in Latin America, as well as examples of innovative practices in mental health) help combat alienation and inequality by working constructively and creatively to generate ways of approaching authority, knowledge, judgement and action.

A concluding, somewhat parochial note: we write this in the wake of the 2015 UK election result, which saw the return to power with a Parliamentary majority (ensuring a 5-year tenure) of a Conservative government committed to reducing public expenditure as a percentage of GDP to levels not seen since before the Second World War, the establishment of the National Health Service and the creation of contemporary mechanisms of social protection (Office for Budget Responsibility, 2014). This will entail, among other consequences, further reductions in social spending additional to those that have already hit the poorest people and regions hardest, against a background of health inequalities that were, on some measures, already more severe than at any point since the Great Depression (and this is using data from before the financial crisis and subsequent selective austerity - Thomas et al, 2010). The effect will almost certainly be to continue the upward redistribution of income and wealth and to worsen the 'neoliberal epidemics' described in recent work by Schrecker and Bambra (2015), adding urgency to the call by several contributors for engaged, activist scholarship that combines academic work with political praxis. Refining explanations of the origins of health inequalities is important, but more sophisticated explanatory models will be little comfort to the casualties of the next 5 years, or their survivors. Absent an effective joining of research and resistance, we dread the body count in 2020 .

\section{About the Authors}

Katherine (Kat) Smith is a Reader at the Global Public Health Unit in the School of Social and Political Science at the University of Edinburgh. Her research focuses on analysing policies affecting public health (especially health inequalities) and better understanding the relationships between health research, policy, advocacy and lobbying. She brought much of this work together in a book, entitled Beyond Evidence Based Policy in Public Health: The Interplay of Ideas. This book is part of a new book series, Palgrave Studies in Science, Knowledge and Policy, which she co-edits with Professor Richard Freeman. More recently, she has been the lead editor for a new edited collection called Health Inequalities: Critical Perspectives, which is being published by Oxford University Press in 2015. She was recently awarded a 2014 Philip Leverhulme Prize for outstanding early career achievements in social policy in the United Kingdom - this award is currently enabling her to undertake some research exploring public understandings of health inequalities evidence, and 
potential policy responses to health inequalities, using deliberative democracy techniques.

Ted Schrecker, in June 2013, left Canada to take up a position as Professor of Global Health Policy at Durham University. A political scientist by background, he came late to the academic world after many years as a legislative researcher and consultant. His major research interests are neo-liberalism; the political economy of health inequalities; issues at the interface of science, ethics, law and public policy; and the social production of scientific knowledge. He is co-author of How Politics Makes Us Sick: Neoliberal Epidemics (Palgrave Macmillan, 2015); editor of the Research Companion to the Globalization of Health (Ashgate, 2012); co-editor of Globalization and Health: Pathways, Evidence and Policy (Routledge, 2009); and author or co-author of numerous articles and book chapters on globalisation and health and, in a previous life, on environmental policy. Perhaps reflecting the discomfort that his perspective causes, at least four of the research institutions where he worked in Canada were subsequently shut down.

\section{References}

Beynon, H., Hudson, R. and Sadler, D. (1994) A Place Called Teesside: A Locality in a Global Economy. Edinburgh, UK: Edinburgh University Press for Durham University.

Harper, S. and Strumpf, E. (2012) Commentary: Social epidemiology: Questionable answers and answerable questions. Epidemiology 23(6): 795-798.

Lewin, K. (1951) Field Theory in Social Science: Selected Theoretical Papers. New York: Harper \& Row. Office for Budget Responsibility. (2014) Economic and Fiscal Outlook: December. London: HMSO.

Ottersen, O.P., Dasgupta, J. and Blouin, C. et al (2014) The political origins of health inequity: Prospects for change. The Lancet 383(9917): 630-667.

Schrecker, T. and Bambra, C. (2015) How Politics Makes Us Sick: Neoliberal Epidemics. Houndmills, UK: Palgrave Macmillan.

Smith, K.E. (2013) Beyond Evidence Based Policy in Public Health: The Interplay of Ideas. Basingstoke, UK: Palgrave Macmillan.

Thomas, B., Dorling, D. and Smith, G.D. (2010) Inequalities in premature mortality in Britain: Observational study from 1921 to 2007. BMJ 341: doi:10.1136/bmj.c3639.

Katherine E. Smith

Global Public Health Unit, School of Social \& Political Science, University of Edinburgh, Edinburgh EH8 9LD UK. E-mail: Katherine.Smith@ed.ac.uk

Ted Schrecker

Centre for Public Policy \& Health, School of Medicine, Pharmacy \& Health, Durham University Queen's Campus, Stockton-On-Tees TS17 6BH UK.

E-mail: theodore.schrecker@durham.ac.uk 